\title{
O EMPREGO DE FERMENTO DE PÃO, Saccharomyces cerevisiae, NA SÍNTESE DE FEROMÔNIOS
}

\author{
Patrícia T. Baraldi e Arlene G. Corrêa*
}

Departamento de Química, Universidade Federal de São Carlos, CP 676, 13565-905 São Carlos - SP

Recebido em 22/1/03; aceito em 27/8/03

\begin{abstract}
BAKER'S YEAST, Saccharomyces cerevisiae, AS A TOOL FOR THE SYNTHESIS OF PHEROMONES. The use of pheromones in integrated pest management has been increasing in the last years due to environmental concern. This development is accompanied by the search for simple, efficient and less aggressive synthetic methodologies for the preparation of pheromones. One of these methodologies includes microbiological reactions, more specifically biocatalytic reduction of carbonyl compounds using baker's yeast (Saccharomyces cerevisiae). This review presents the use of baker's yeast as an easy and cheap alternative to obtain enantiomerically enriched compounds employed in the synthesis of pheromones.
\end{abstract}

Keywords: pheromones; baker's yeast; synthesis.

\section{INTRODUÇÃO}

O termo feromônio (pherein $=$ transferir, hormon $=$ excitar) foi criado em 1959 e definido como um sinal químico de ação intraespecífica, que pode atuar de forma prolongada na fisiologia e desenvolvimento de insetos, neste caso denominados "preparadores", ou provocar uma ação imediata no comportamento dos indivíduos, apresentando efeito tipo "desencadeador". Esses feromônios podem agir como atraentes sexuais, marcadores de trilhas, propiciar comportamento de agregação, alarme, dispersão, entre outros ${ }^{1}$.

Os feromônios sexuais podem ser usados no monitoramento, confundimento e captura massal dos insetos-pragas com a finalidade de reduzir o nível populacional da praga e também a quantidade de inseticidas tradicionais aplicada nas lavouras. O monitoramento é a técnica que identifica o momento certo em que a praga entra na lavoura, em que nível se estabelece, como reage aos inseticidas e quais são os seus ciclos de vida. O confundimento consiste em aplicar, num momento crítico de crescimento da população da praga na lavoura, uma grande quantidade de feromônio sexual, por um certo período, impedindo que o inseto encontre a trilha de feromônio natural que está sendo emitido por um indivíduo de sexo oposto, impedindo assim que haja o acasalamento. Na captura massal usa-se um grande número de armadilhas contendo feromônio, esperando interromper o crescimento populacional da praga, impedindo que haja dano econômico na cultura ${ }^{1}$.

Desde a década de 70, os feromônios têm ganhado considerável interesse como alternativa frente aos inseticidas convencionais e vêm se tornado uma área importante dentro da química de produtos naturais ${ }^{2}$. Os feromônios são únicos para cada inseto, ou seja, cada espécie possui o seu próprio "código" de comunicação baseado nas diferenças estruturais dos compostos, ou na proporção desses compostos ${ }^{1}$. Isto é necessário para que na natureza não haja reprodução ou outro tipo de interação entre indivíduos de espécies distintas ${ }^{2}$. Uma diferença estrutural que está relacionada com a atividade biológica é a quiralidade da molécula, por exemplo: a broca-do-tronco-da-pereira, Gnathotricus sulcatus (Coleoptera: Platypodidae), responde à mistura de $65 \%$ do isômero $(S)$-(+)-sulcatol (1) e 35\% do isômero $(R)-(-)-1$ e não responde a nenhum dos isômeros separados $(S)-(+)-$

*e-mail: agcorrea@power.ufscar.br
1 e (R)-(-)-1 (Figura 1). Uma outra espécie, G. retusus, besouros da ambrosia, importante praga nas florestas de coníferas da Costa do Pacífico Norte, é sensível apenas ao isômero $S$ e a resposta é inibida pela ação do $R^{3,4}$.

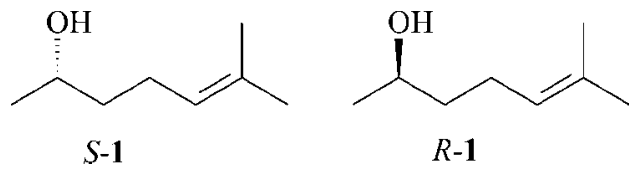

Figura 1. Enantiômeros do sulcatol (1)

Outro fator estrutural que aparece em moléculas que são aquirais é a geometria das duplas ligações. Por exemplo, o bombicol (2), que é o atraente sexual produzido pelas fêmeas do bicho-da-seda, Bombyx mori (Lepidoptera: Bombycidae), possui uma dupla ligação com geometria $E$ - na posição 10 , e $Z$ - na posição 12 (Figura 2).

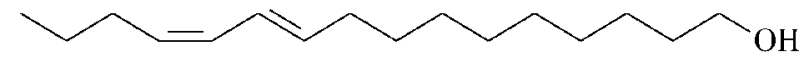

Bumbicol (2)

Figura 2. Bombicol (2), atraente sexual do bicho-da-seda

A fim de sintetizar os compostos com a estereoquímica correta do produto natural bioativo várias metodologias têm sido empregadas como, por exemplo, na síntese de feromônios de cadeia linear insaturada, utilizam-se acetilenos, reações de Wittig e co-relatas. Feromônios que contêm centros assimétricos normalmente são preparados a partir de compostos com configuração absoluta conhecida e/ou através de síntese estereosseletiva empregando auxiliares quirais, catalisadores quirais, ou mesmo a catálise enzimática ${ }^{2,5}$.

A utilização de reações catalisadas por enzimas isoladas ou microrganismos tem se tornado mais popular devido à alta estereosseletividade que estas apresentam. O fermento de pão, Saccharomyces cerevisiae, é um dos biocatalisadores mais comuns, devido principalmente a: fácil disponibilidade; o baixo custo; não requerer instrumentos especiais; o manuseio dispensa a ajuda de um microbiologista ou técnicas da microbiologia; fácil manipulação; não ser patogênico; eficiência em relação a catalisadores convencionais e poder trabalhar à temperatura ambiente ${ }^{6}$. 
No entanto, algumas desvantagens do uso do fermento de pão são: pouca solubilidade em água do substrato orgânico (podendo-se utilizar etanol ou outros co-solventes ${ }^{7}$; presença de um sistema multienzimático intra e extracelular (assim, a seletividade pode algumas vezes ser aumentada pela modificação no substrato, ou mudanças no meio reacional e/ou adição de inibidores) ${ }^{8}$; existência de diferentes cepas (podem interferir na reprodutibilidade do experimento $)^{7}$.

As reações utilizando fermento de pão têm sido empregadas na obtenção de intermediários sintéticos ${ }^{9}$ ou de síntons quirais não disponíveis comercialmente ${ }^{10}$, que são utilizados na síntese de feromônios. Por exemplo, pode-se citar a síntese realizada por Mori e Takikawa ${ }^{11}$ da $(3 S, 11 R)$-3,11-dimetil-2-nonacosanona (3), feromônio produzido pelas fêmeas da barata, Blattella germanica (Orthoptera: Blattellidae), ou da (5Z,13S)-5-tetradecen-13-olida (4), sinergista do feromônio de agregação dos besouros do grão, Cryptolestes pusillus (Coleoptera: Cucujidae) (Figura 3) ${ }^{12}$.

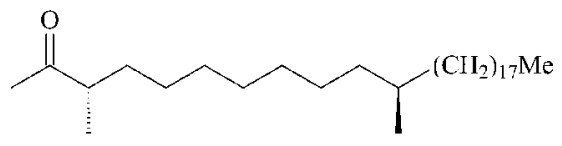

$(3 S, 11 R)-\mathbf{3}$

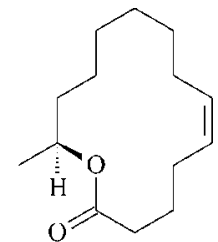

S- 4
Figura 3. Exemplos de feromônios que foram sintetizados empregando fermento de pão

As enzimas que estão presentes no meio celular da levedura são as oxidorredutases, que podem ser subdivididas em oxidases, oxigenases e desidrogenases (DHs). Dentre essas, as álcool desidrogenases (ADHs) e a lactato desidrogenases são as enzimas responsáveis pela catálise na redução estereosseletiva de compostos carbonílicos e derivados ${ }^{13}$.

O processo de atuação das DHs requer a presença de cofatores (coenzimas) que são os responsáveis pela transferência de hidrogênio, no caso das biorreduções. Devido ao alto custo, estes cofatores não são utilizados em quantidade estequiométrica, sendo necessário, portanto um sistema de regeneração in situ. A maioria das DHs utiliza cofatores do tipo nicotinamidas $\mathrm{NAD}(\mathrm{P}) \mathrm{H}$, que podem ser reciclados através de métodos químicos ou enzimáticos. A relação enzima-coenzima pode ser classificada de diferentes maneiras como apresentado pela Figura 4.

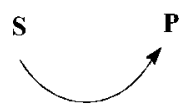

E

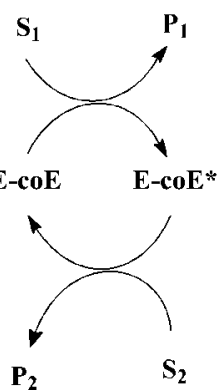

B

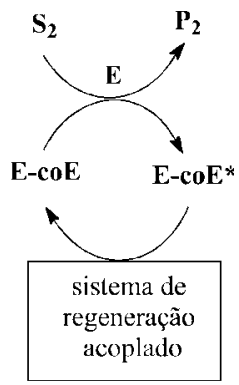

C
A

A - Enzima sem coenzima: não exigem cofatores

B - Enzima com coenzima fortemente ligada: o cofator está fortemente preso à proteina c, portanto, a regeneração do cofator é conseguida de modo automático, por exemplo, certas metaloproteínas e enzimas dependentes de piridoxal C - Fnzima com coenzima adicionada: as enzimas requerem a adição de cofatores tais como $\mathrm{NAD}(\mathrm{P}) \mathrm{H}, \mathrm{ATP}, \mathrm{CoA}-\mathrm{SH}$, para sua ativação.

Figura 4. Tipos de relação enzima-coenzima
Além da necessidade de cofatores, outro aspecto mecanístico nas biotransformações é a relação do substrato com o sítio ativo da enzima, para a qual várias teorias têm sido desenvolvidas com o objetivo de entender o processo da catálise enzimática. Entre estas pode-se citar o mecanismo chave e fechadura, do estado induzido, teoria da dessolvatação e dos três pontos ${ }^{14}$.

A teoria dos três pontos é amplamente usada para explicar a enantiosseletividade das enzimas e foi sugerida por Ogston ${ }^{14}$. Para obter um alto grau de enantiosseletividade, um substrato deveria ser firmemente preso no espaço em 3 dimensões. Entretanto, eles deveriam ter pelo menos 3 pontos diferentes de ataque do substrato no sítio ativo. Isto exemplifica a discriminação dos enantiômeros do substrato racêmico 1 e 2 (Figura 5) com a quiralidade localizada no átomo de carbono $s p^{3}$. Para compostos que possuem uma quiralidade axial ou planar envolvendo um átomo de carbono $s p$ ou $s p^{2}$, respectivamente, figuras análogas são criadas. No caso I, o enantiômero A é um bom substrato permitindo uma interação ótima dos grupos (A, $\mathrm{B}, \mathrm{C})$. Isto garante uma orientação ótima do grupo reativo (D) através do operador químico, o qual é requerido para transformação bem sucedida. Nos casos II a IV, o enantiômero B é um substrato pobre porque a ligação ótima e orientação do grupo D não são possíveis. Assim, uma catálise pobre seria observada.

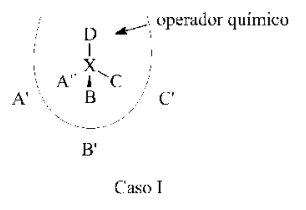

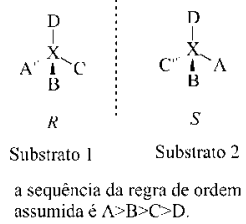

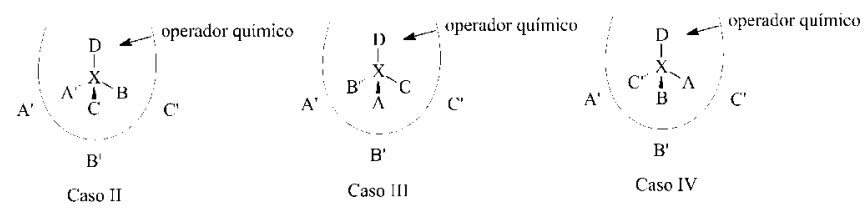

Figura 5. Representação esquemática da discriminação enzimática dos enantiômeros

O fermento de pão pode ser empregado na redução de carbonilas de cetonas e aldeídos, nitrilas, $\alpha$ - e $\beta$-cetoésteres e análogos e duplas ligações $\mathrm{C}=\mathrm{C}$. Alguns trabalhos têm sido realizados com o intuito de se verificar o mecanismo e a estereosseletividade destas reações. Fuganti e colaboradores estudaram a redução da furilacroleína que leva ao álcool 5, um material de partida muito utilizado em síntese. Foi verificado que na primeira hora de reação, a carbonila é reduzida formando o álcool insaturado 6 (Figura 6) ${ }^{15}$. Este por sua vez é reoxidado ao aldeído 7 e somente após 3 a 4 dias o álcool saturado 5 é obtido. Deste modo, ocorre a adição trans do hidrogênio à dupla ligação de 7 (o hidrogênio na posição 2 é adicionado pró- $R$ ), levando ao aldeído saturado, que é então reduzido pela adição de um átomo de hidrogênio pró- $R$ levando ao álcool 5 . O equilíbrio aldeído álcool é fortemente deslocado para o álcool com as condições reacionais.

A estereosseletividade na redução de carbonilas pode ser visualizada pela regra de Prelog como mostrado no processo $8 \rightarrow \mathbf{9}$ (Figura 7). A carbonila de 8 é reduzida assimetricamente com fermento para render o álcool 9 . Se o volume de $G$ (grupo grande; mais volumoso) não é tão diferente de $P$ (grupo menor), o produto 9 teria baixa pureza ótica. Então deveria ser possível obter ambos os enantiômeros de um álcool pela mudança de tamanho dos dois substituintes ligados no grupo carbonila, desejavelmente em rendi- 


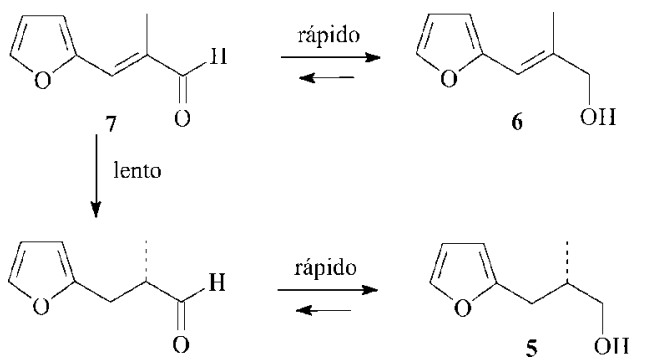

Figura 6. Redução da furilacroleína com fermento de pão

mento ótico alto, um pode ajustar a diferença entre o volume de dois substituintes na condição desejada ${ }^{16}$. Na Figura 7 pode-se observar que a redução do acetoacetato de etila fornece o álcool com configuração $S$ e $e e-90 \%$, enquanto que o 3-oxopentanoato de etila fornece o álcool $R$ com $e e-40 \%$, devido provavelmente à similaridade de tamanho entre os grupos vizinhos à carbonila.<smiles></smiles><smiles>CCOC(=O)CC(O)CC(O)CC(=O)OCC</smiles>

$S$<smiles>[R]C(CC(=O)OCC)CC(O)CC(=O)OCC</smiles>

Figura 7. Efeito dos substituintes na redução de $\beta$-cetoésteres

Algumas revisões sobre síntese de feromônios são encontradas na literatura. Por exemplo, Mori, em um amplo estudo, relatou os trabalhos publicados no período de 1979-1989 ${ }^{17}$; as sínteses de vários feromônios, empregando-se métodos químicos e biológicos, no período de 1990-1998, foram relatadas por Koutek et al. ${ }^{2}$; Högberg et al. relataram a biocatálise como ferramenta para a preparação de blocos construtores na síntese de alguns feromônios ${ }^{8}$.

O objetivo deste trabalho foi fazer uma revisão sobre os feromônios sintetizados que empregaram fermento de pão, $S$. cerevisiae, em pelo menos uma das etapas reacionais, como uma ferramenta para a obtenção de intermediários quirais. Será demonstrado que os intermediários obtidos através de reações de redução de $\beta$-cetoésteres e análogos, ou de sistemas carbonílicos $\alpha$-metil- $\alpha, \beta$ insaturados, podem ser utilizados na preparação de compostos com estruturas químicas bastante diferenciadas. Para facilitar a discussão, os feromônios foram divididos de acordo com a função orgânica presente na sua estrutura, tornando possível também uma comparação entre as diferentes metodologias sintéticas para a obtenção de uma mesma classe de compostos feromonais.

\section{ALCANOS}

Uma mistura de $(5 S, 9 S)$-5,9-dimetil-heptadecano (10a), principal componente do feromônio sexual do bicho mineiro do café, Leucoptera scitella (Lepidoptera: Lyonetiidae), e seu isômero $(5 R, 9 S)$-11a foram sintetizados tendo como precursor o $(R)$-citronelal
(12). Este foi obtido através de resolução cinética do citronelal racêmico com fermento de pão, que reduziu seletivamente o enantiômero $S$-12 levando ao álcool 13. A síntese dos compostos 10a e 11a foi realizada com rendimento global de $22 \%$ em 5 etapas $(\text { Esquema } 1)^{18}$. Os isômeros $(5 R, 9 S)$-10b e $(5 S, 9 S)$-11b, possíveis atraentes sexuais da Perileucoptera coffeella (=Leucoptera coffeella), foram preparados de maneira análoga.

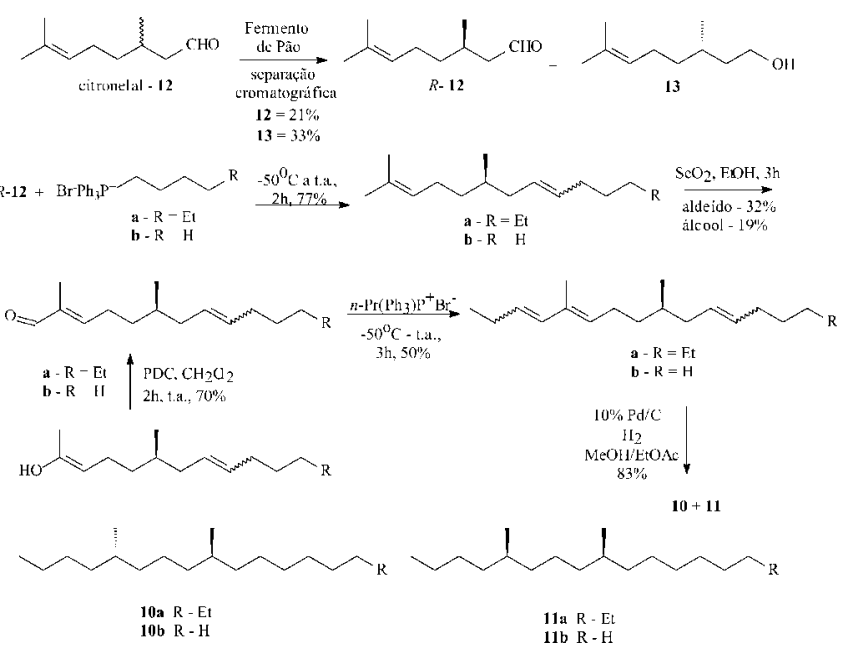

Esquema 1

O (5S)-2,5-dimetil-heptadecano (14) e (7S)-metil-heptadecano (15) participam da mistura feromonal da lagarta enroladora, Lambdina fiscellaria lugubrosa (Lepidoptera: Geometridae) ${ }^{11}$. A síntese destes compostos foi realizada a partir da redução do aldeído $\mathbf{1 6}$ com fermento de pão, seguido de tratamento com cloreto de tosila para fornecer o composto 16a, que foi utilizado como sínton quiral (Esquema 2).

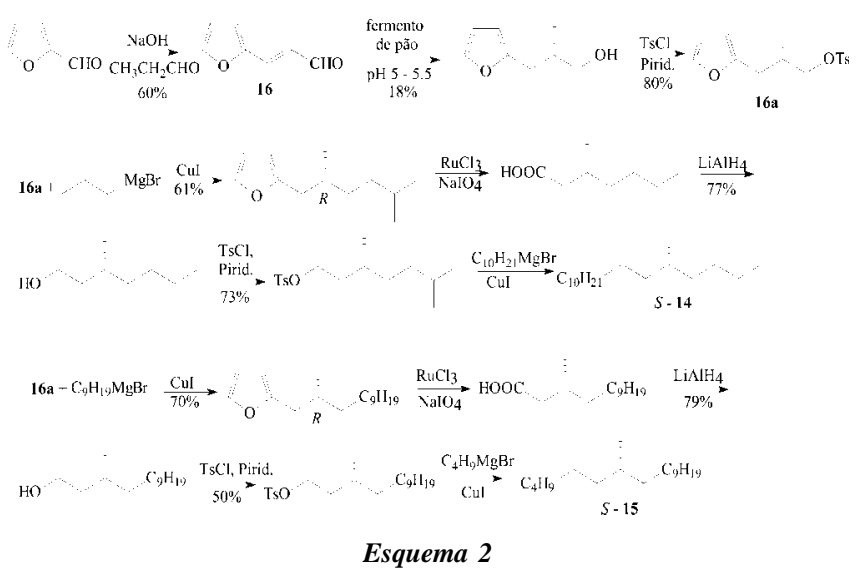

3,13-dimetil-heptadecano (17) foi recentemente relatado como sendo o componente majoritário do feromônio da lagarta falsa enroladeira, Nepytia freemani (Lepidoptera: Geometridae). O estereoisômero de maior resposta eletrofisiológica foi o $(3 S, 13 R)$ 17, mas os outros 3 estereoisômeros também foram ativos. A mistura dos 4 estereoisômeros foi 3,6 vezes mais ativa em campo que $(3 S, 13 R)$-17. Os 4 estereoisômeros foram sintetizados, mas apenas na síntese de $(3 S, 13 R)-17$ o fermento de pão foi utilizado ${ }^{19}$. A síntese deste composto foi realizada a partir da redução do aldeído 16 com fermento de pão, de acordo com o procedimento descrito por 
Fuganti ${ }^{20}$ (Esquema 3) e, em seguida, levado ao composto 18, a fim de preparar o intermediário 19.

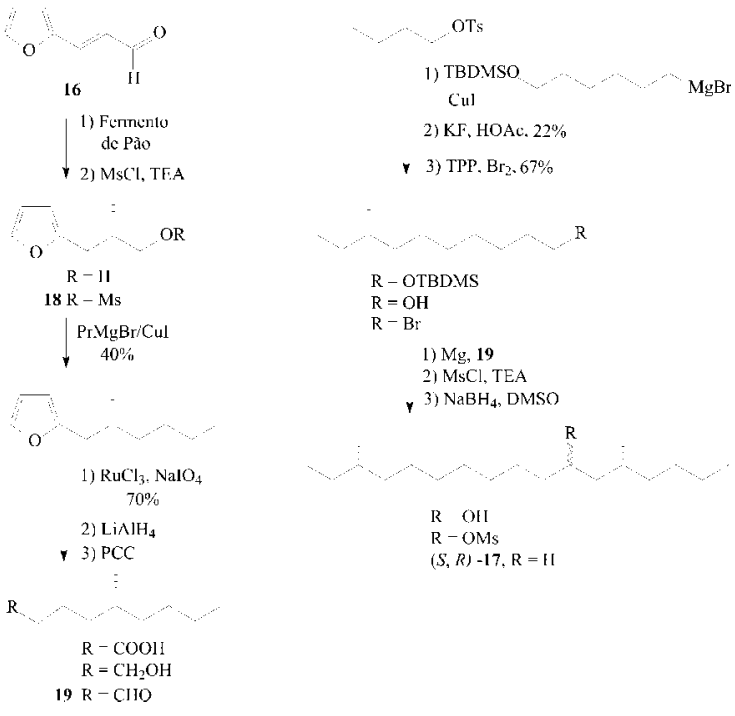

Esquema 3

\section{EPÓXIDOS}

Dispalure, $(7 R, 8 S)-(+)-7,8$-epoxi-2-metil-octadecano (20), é o feromônio da mariposa cigana, Lymantria díspar (Lepidoptera: Lymantriidae). Na síntese deste feromônio, o material de partida é o $\beta$-cetossulfóxido 21 racêmico, que foi submetido à resolução cinética com fermento de pão fornecendo o sulfóxido $S$-21, que pode ser separado do produto de redução de $R-21$ (Esquema 4$)^{21}$. Encontra-se ainda na literatura uma outra metodologia para a preparação de $\mathbf{2 1}$ utilizando também fermento de pão ${ }^{17}$.

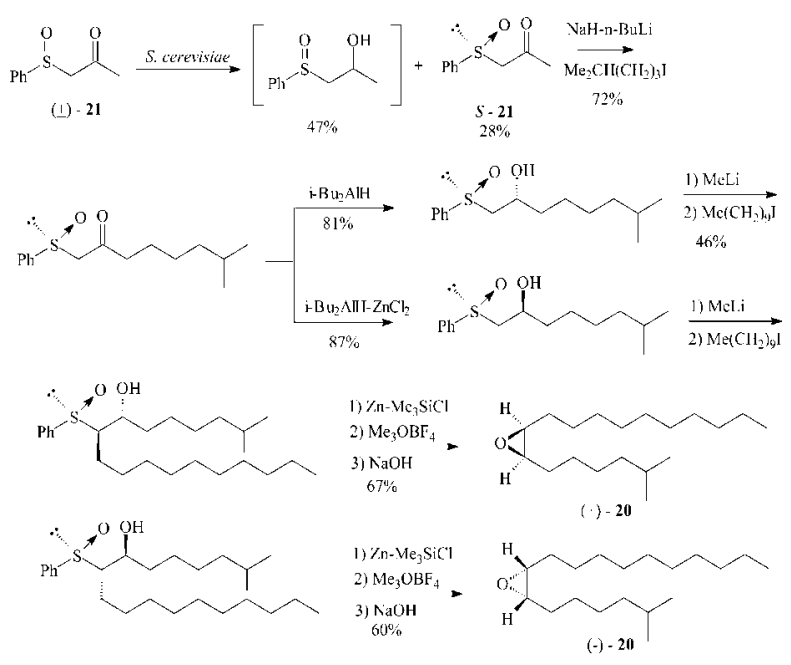

Esquema 4

\section{ÁLCOOIS E SEUS ÉSTERES}

O (3S,4S)-4-metil-3-heptanol (22) é o componente do feromônio de agregação do besouro do tronco do elmo, Scolytus multistriatus (Coleoptera: Scolytidae). Hoffmann et al. utilizaram o $\beta$-cetoéster cíclico 23 para fornecer o hidroxiéster 24 com $e e=83 \%$. A hidrólise deste, seguido de formação de um sal amônio quaternário e recristalização, forneceu o ácido 25 com $e e>95 \%$ (Esquema 5$)^{22}$. O isômero $(3 R, 4 R)-\mathbf{2 2}$ pode ser obtido pela redução enantiosseletiva de 3-oxopentanoato de etila também utilizando fermento de pão ${ }^{17}$.

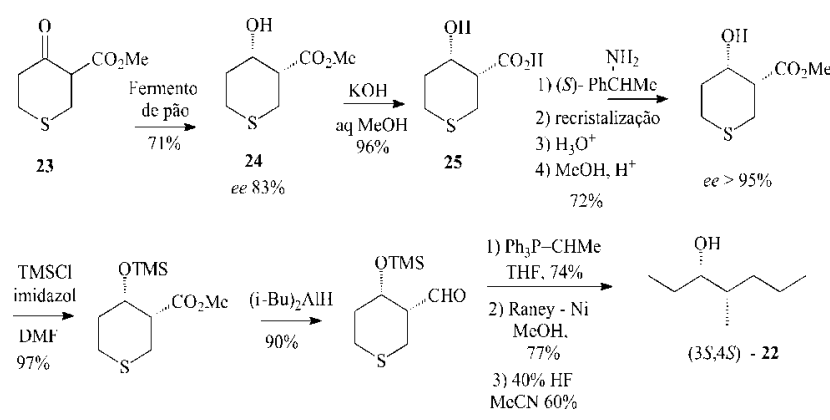

Esquema 5

O feromônio sexual da fêmea da praga da raiz do milho, Diabrotica virgifera virgifera LeConte (Coleoptera: Chrysomelidae), foi isolado e identificado como sendo o propanoato de 8-metil-2decanoila (26), porém a correta estereoquímica dos centros 2 e 8 é desconhecida. A síntese descrita por Ferreira et al. forneceu dois diastereoisômeros: $(2 S, 8 S)$-26 e $(2 S, 8 R)$-26, utilizando o intermediário 27, que contém o centro assimétrico gerado na redução com fermento de pão do acetoacetato de etila (Esquema 6) ${ }^{23}$. Os diastereoisômeros $(2 R, 8 R)$ - e $(2 S, 8 R)$-26 foram preparados por Mori e Watanabe através de outra rota sintética que também utiliza o intermediário $S$-27 obtido na redução microbiológica ${ }^{17}$.

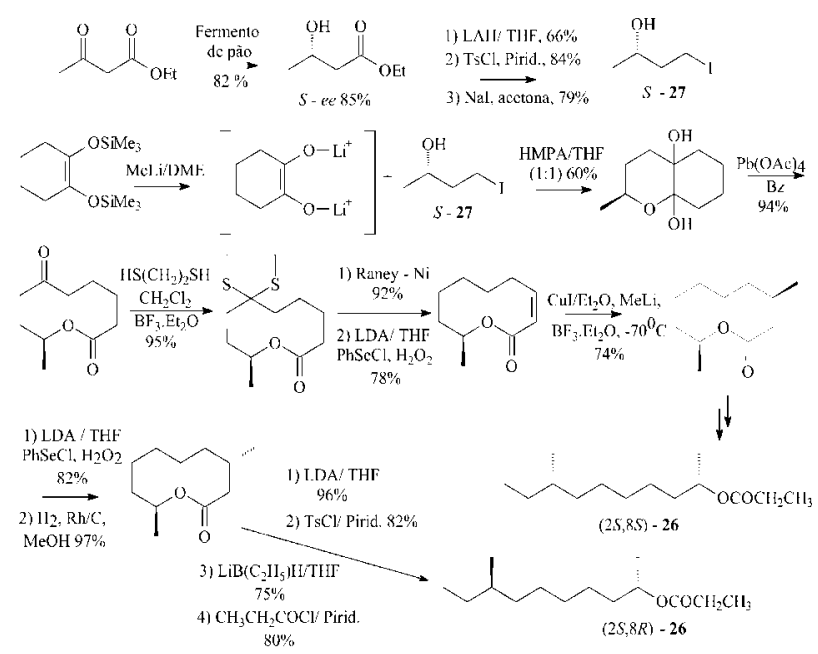

Esquema 6

Os ésteres derivados do 3,7-dimetil-2-pentadecanol (28), diprionol, são atraentes sexuais de dois gêneros da mosca do pinheiro pertencentes aos gêneros Diprion e Neodiprion (Hymenoptera: Diprionidae). O reconhecimento entre as espécies é devido ao fato destas utilizarem os estereoisômeros desses ésteres em diferentes proporções. Por exemplo, a mosca branca do pinheiro, Neodiprion pinetum, emprega o acetato (2S,3S,7S)-29 como componente majoritário, enquanto que a mosca que ataca o pinheiro escocês, Neodiprion sertifer, utiliza o $(2 S, 3 S, 7 S)$ 28. A rota sintética que fornece os compostos 28 e 29 se baseia no emprego do fermento de pão para a obtenção de dois intermediários através da síntese convergente ${ }^{23}$ (Esquema 7).

O sulcatol, (S)-(+)-6-metil-hept-5-en-2-ol (1) foi obtido por Belan et $a .^{3}$ pela redução microbiológica altamente estereosseletiva com $S$. cerevisae $^{3}$ de 6-metil-hept-5-en-2-ona (30). O isômero $R$, entretanto, foi obtido utilizando outro microrganismo. 


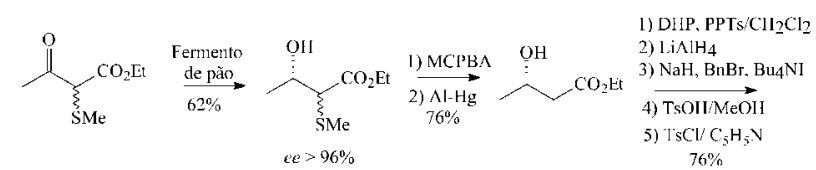

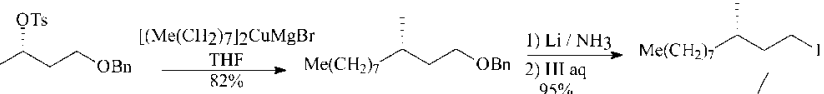

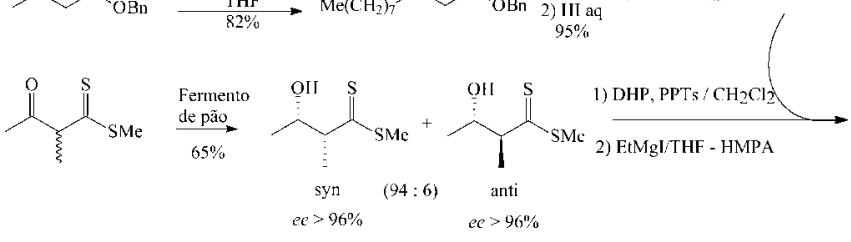

$$
\text { (1S,2S,6S)-29}
$$

Esquema 7

A 6-metil-hept-5-en-2-ona (30) também foi utilizada como material de partida para a síntese em 4 etapas do $(2 R, 5 S)$-pitiol $(\mathbf{3 1})^{25}$, um atraente específico do besouro macho, Pityophthorus pityographus (Coleoptera: Scolytidae) (Esquema 8). A síntese assimétrica em 7 etapas deste feromônio foi descrita também por Mori et al., sendo que a etapa chave é a redução estereosseletiva do acetoacetato de etila empregando fermento de pão ${ }^{17}$.

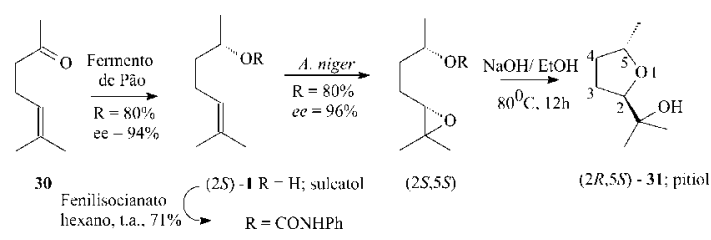

Esquema 8

Outro exemplo é o 2-metil-4-octanol (32), componente do feromônio de agregação produzido pelos machos de besouros da família Curculioniadae: Metamasius hemipterus (broca pequena da cana), Sphenophorus levis (gorgulho da cana-de-açúcar) e Rhabdoscellus obscurus. Baraldi et al. relataram a síntese enantiosseletiva do $(R)$ 33 a partir da redução com fermento de pão do $\beta$-cetoéster 33 utilizando como inibidor enzimático o álcool alílico, a fim de obter o hidroxiéster na configuração $S$ com alto excesso enantiomérico (Esquema 9) ${ }^{7}$

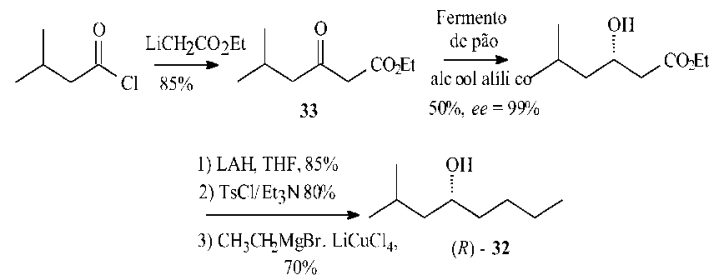

Esquema 9

O acetato de $(R)$-10-metildodecan-1-ila (34), componente feromonal de Adoxophyes sp. (Lepidoptera: Tortricidae), foi sintetizado através da redução microbiológica empregando fermento de pão de um $\beta$-cetoéster para a obtenção do intermediário-chave $(R)$ 2-metilbutan-1-ol (35) (Esquema 10) ${ }^{10}$

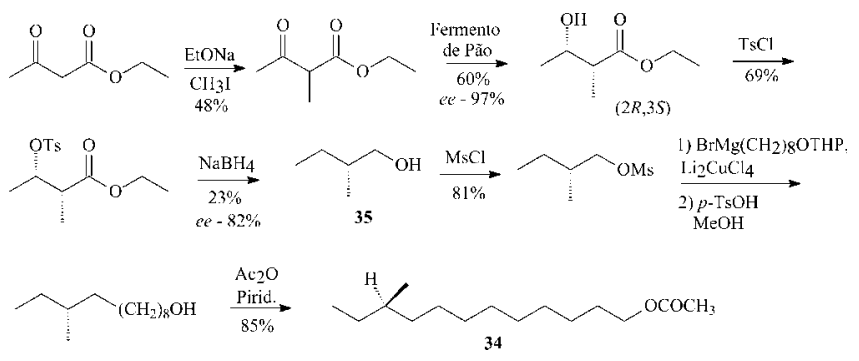

Esquema 10

O composto (S,E)-1-metil-9-dodecenila (36) foi isolado e identificado como sendo o feromônio sexual da fêmea da mosca Mayetiola destructor Say (Diptera: Cecidomyiidae), que é uma das mais destrutivas pragas no trigo ${ }^{26}$. Duas sínteses para o composto 36 são descritas e notavelmente os autores utilizam o mesmo intermediário sintético (S)-3-hidroxibutanoato de etila (37), que é obtido pela redução com fermento de pão do acetoacetato de etila. Kharisov (Esquema $11)^{27}$ utiliza uma linhagem de fermento "80-1", enquanto que Takeuchi (Esquema 12) utiliza o fermento comercial ${ }^{28}$.

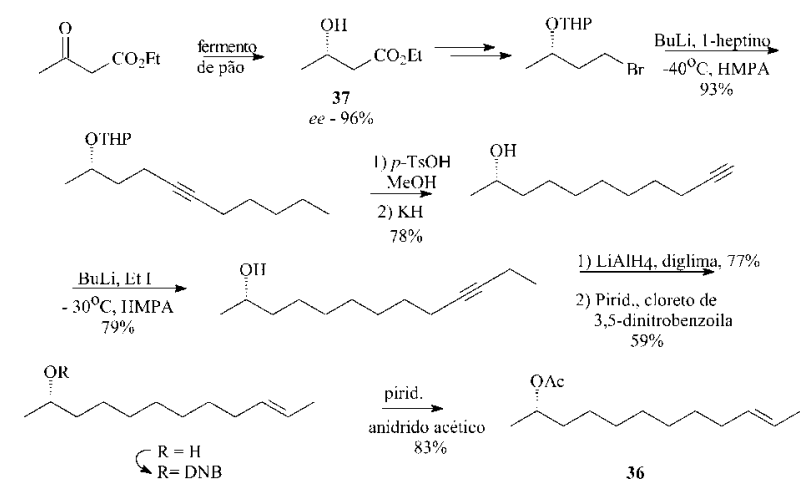

Esquema 11

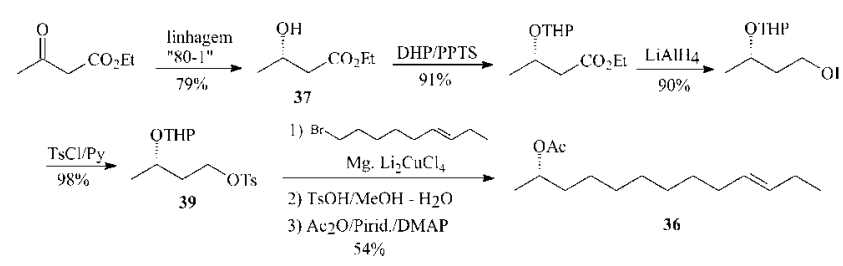

Esquema 12

Kharisov utilizou o mesmo intermediário sintético 39 na síntese de outro composto versátil o (2S)-tridecilacetato (38), que foi identificado como sendo o feromônio da mosca da fruta Drosophila mulleri (Diptera: Drosophilidae), que causa grandes danos em plantações de trigo (Esquema 13) ${ }^{27}$.

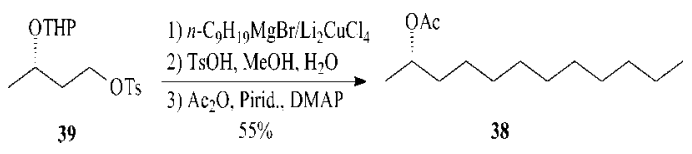

Esquema 13

\section{ALDEÍDOS}

O tribolure, $(4 R, 8 R)$-4,8-dimetildecanal (40), foi identificado como feromônio de agregação do gorgulho-vermelho, Tribolium 
castaneum (Coleoptera: Tenebrionidae), embora não seja ativo isoladamente ${ }^{15}$. Na síntese de 40, o aldeído $\mathbf{1 6}$ foi submetido à redução microbiológica utilizando fermento de pão, fornecendo o álcool correspondente com $e e>99 \%$ (Esquema 14).

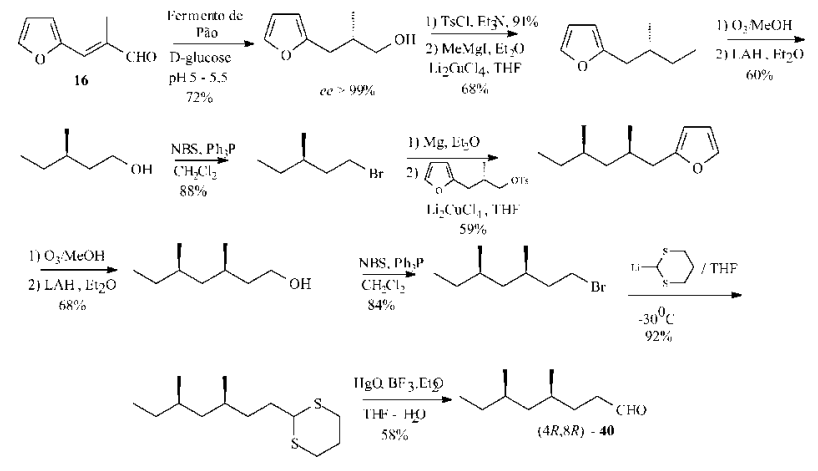

Esquema 14

\section{CETONAS}

Burkholder e colaboradores ${ }^{29}$ isolaram o feromônio de agregação da bicheira-da-raiz-do arroz, Sitophilus orizae (Coleoptera: Curculionidae), e do gorgulho do milho, S. zeamais, responsáveis pela infestação de estoques de cereais. Este feromônio foi identificado como sendo o 4-metil-5-hidroxi-heptan-3-ona (41) e nomeado de sitofilure. A síntese dos quatro possíveis estereoisômeros foi realizada e os compostos foram submetidos a bioensaios, que revelaram que o enantiômero $(4 S, 5 R)$-(41) é a forma ativa do feromônio.

Algumas sínteses foram relatadas para esse composto, sendo que a mais curta apresentada na literatura é a descrita por Fujisawa, que emprega o fermento de pão para reduzir regio- e enantiosseletivamente 3-acetiltetra-hidrotiopiran-4-onas (42) para formar predominantemente $(3 R, 4 S)$-3-acil-4-hidroxitetra-hidrotiopiranos $(\mathbf{4 3})$ com alta pureza enantiomérica (Esquema 15) ${ }^{30}$.

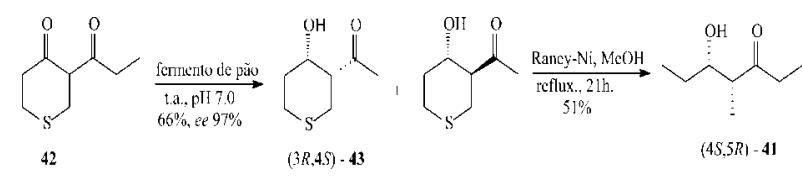

Esquema 15

Fuganti fez a redução da hidroxicetona que forneceu o diol $\left(3 S, 4 R\right.$ ) levando ao composto 41 (Esquema 16) ${ }^{31}$. Pilli parte do $\beta$ cetoéster que, após redução com fermento de pão na presença de cloroacetato de etila e alquilação, levou ao hidroxiéster com configuração $(2 S, 3 S)$ - e após 10 etapas leva ao composto $\mathbf{4 1}$ desejado (Esquema 17) ${ }^{32}$.

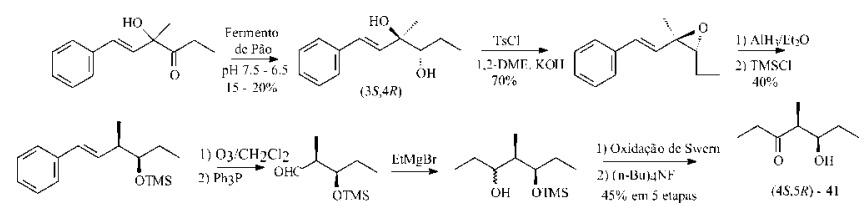

Esquema 16

A (-)-serricornina, $(4 S, 6 S, 7 S)$-7-hidroxi-4,6-dimetil-3-nonanona (44), é o feromônio sexual das fêmeas do besourinho do fumo, Lasioderma serricorne (Coleoptera: Anobiidae). Somente o isômero

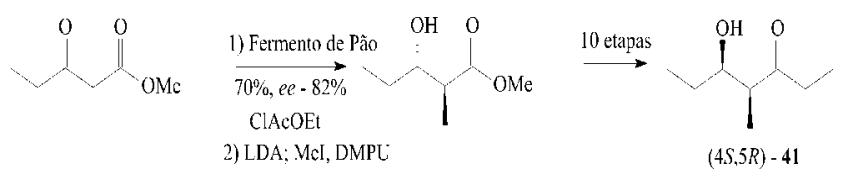

Esquema 17

(4S,6S,7S)-44 mostrou atividade feromonal, enquanto que o isômero $(4 S, 6 S, 7 R)-44$ inibe sua ação. Algumas metodologias aplicando biocatálise são descritas para este composto ${ }^{17}$. Um exemplo é a metodologia empregada por Pilli et al. que faz o controle estereoquímico da redução microbiológica utilizando álcool alílico como inibidor enzimático (Esquema 18) ${ }^{33}$.

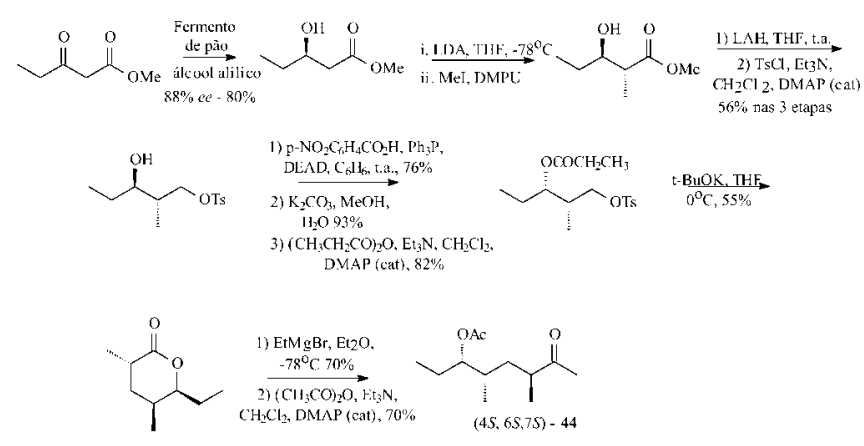

Esquema 18

O feromônio sexual do besouro da uva, Xylotrechus pyrrhoderus (Coleoptera: Cerambycidae), importante praga das vinhas japonesas, foi identificado como uma mistura de $(+)-(2 S)$-2-hidroxioctan3-ona (47) e (-)-(2S,3R)-octano-2,3-diol (45), na razão de 20:80 ou 5:95. A síntese destes compostos foi realizada em uma etapa a partir da $\alpha$-dicetona (46) (Esquema 19) ${ }^{34}$.

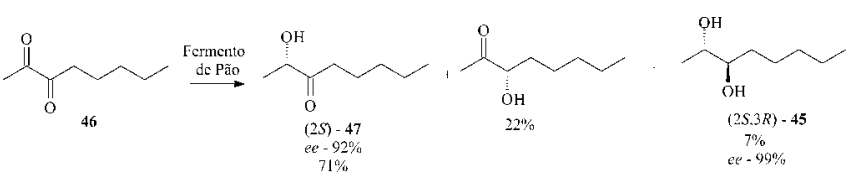

Esquema 19

\section{LACTONAS}

A 4-hexanolida (48) foi isolada como componente feromonal do besouro dermestídeo Trogoderma glabrum (Coleoptera: Dermestidae) e do besouro T. granarium. Para T. glabrum nenhum dos enantiômeros $(R)$ ou $(S)$ foram sinergísticos, enquanto que $T$. granarium responde apenas ao $(R)-\mathbf{4 8}$, mas não ao $(S)-48$ ou à mistura racêmica.

Algumas metodologias utilizando fermento de pão têm sido empregadas para a síntese desse composto ${ }^{17,35}$. A síntese do isômero $S$ foi realizada por Kozikowski et al., que reduziram uma fenilsulfona com fermento de pão (Esquema 20) ${ }^{36}$. Fujisawa et al. fizeram a redução de uma $\beta$-cetossulfona com fermento de pão para fornecer o isômero $R$ (Esquema 21$)^{37}$.

A $(R)-(-)-(Z)-5$-tetradecenolida (49), feromônio sexual produzido pela fêmea de um importante besouro japonês, Popilia japonica (Coleoptera: Scarabaeidae), mostrou-se ativa apenas oticamente pura. A síntese formal estereosseletiva deste composto foi realizada a partir do 5-metil-hex-4-enal que, após algumas reações, forneceu o intermediário 1-hidroxi-6-metil-hept-5-en-2-ona (50), que é então reduzido com fermento de pão (Esquema 22) ${ }^{38}$. 


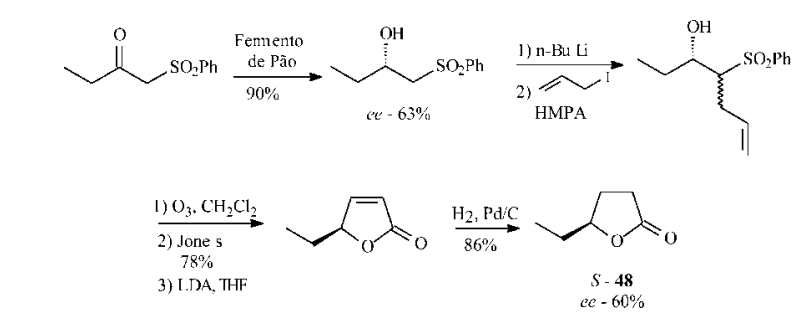

Esquema 20

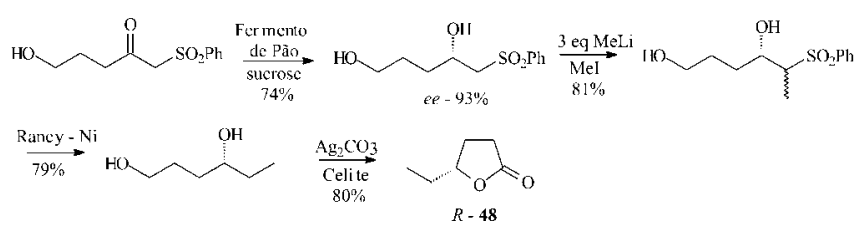

Esquema 21

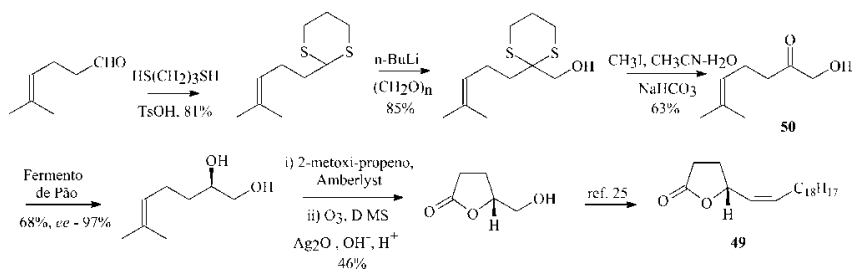

Esquema 22

A cis-2-metil-5-hexanolida (51) foi isolada como componente majoritário da mistura feromonal da abelha carpinteira, Xylocopa hirsutissima (Hymenoptera: Anthophoridae). A síntese de $(2 R, 5 R)$ 51 foi feita através da combinação do uso de fermento de pão e alquilação do enolato derivado da amida 52 com o iodeto 53 (Esquema 23) $)^{39}$.

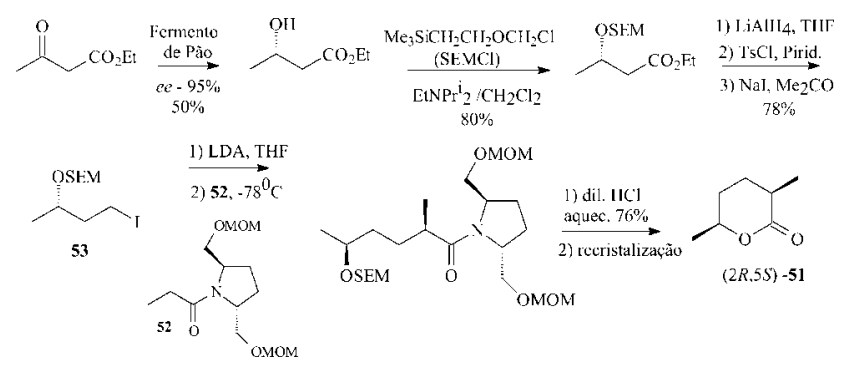

Esquema 23

A 4-dodecanolida (54) é uma secreção defensiva do besouro Bredius mandibularis ${ }^{17}$. Três sínteses quirais desse composto foram realizadas pela redução com fermento de pão. Por exemplo, Rao et al. utilizaram tiofeno como um extensor de cadeia (Esquema 24). Pela redução de $\mathbf{5 5}$ com fermento de padaria foi obtida a lactona $\mathbf{5 4}$ na configuração $R$.

A $(R)$-5-hexanolida (56) foi isolada da cabeça da abelha rainha oriental, Vespa orientalis (Vespidae: Vespinae), como um feromônio para estimular as operárias na construção das células da colméia, sendo que apenas a lactona com configuração $R$ foi bioativa. A lactona $S$ foi sintetizada por dois diferentes métodos, utilizando fermento de padaria $^{40}$. A lactona $R$ também foi obtida da redução enantiosseletiva do 5-oxo-hexadecanoato de potássio (57) com fermento de pão com alta enantiosseletividade (Esquema 25) ${ }^{41}$. Similarmente, Bhalerao et al. utilizaram tiofeno como extensor de cadeia ${ }^{17}$.

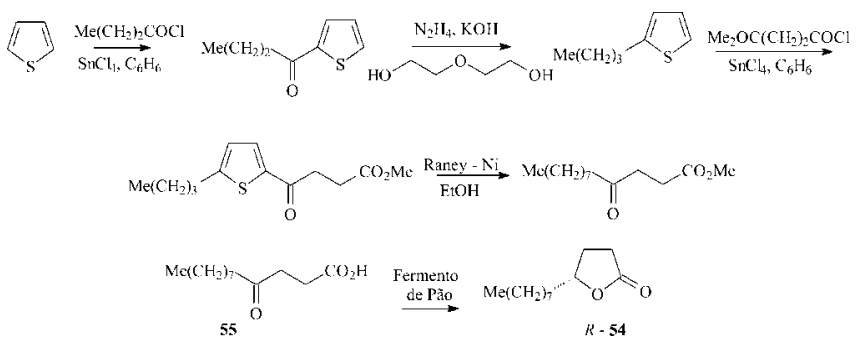

Esquema 24

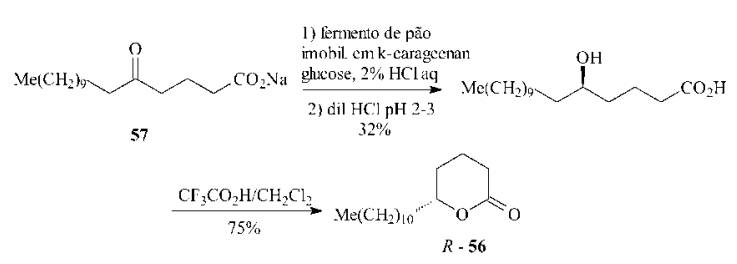

Esquema 25

A síntese formal da $(5 R, 6 S)$-6-acetoxi-5-hexadecanolida $(\mathbf{5 8})$, componente majoritário do atraente feromonal de oviposição do pernilongo, Culex pipiens fatigans (Diptera: Culicidae), foi feita pela redução do ( \pm )-clorocetoéster 59 com fermento de pão fornecendo a mistura dos compostos 60a e 60b, que foi separada por cromatografia líquida de alta eficiência (Esquema 26). O hidroxiéster 60b foi convertido ao epóxido 61, intermediário para a síntese de $\mathbf{5 8}^{17,42}$.

$$
\text { 601b } \frac{\mathrm{VaBHH}_{4}}{76 \% \%}
$$

Esquema 26

A $(5 Z, 13 S)$-5-tetradecen-13-olida (4) é sinergista do feromônio de agregação dos besouros do grão, Cryptolestes sp. Para a espécie C. pusillus apenas o isômero $S$ foi descrito como ativo, enquanto que outra espécie, C. turcicus, produz uma mistura de 33:67 dos isômeros $R$ e $S$. A síntese realizada por Naoshima et al. utiliza o cetoácido 62 para fornecer o hidroxiácido 63 com fermento de pão imobilizado (Esquema 27) ${ }^{12,17}$.

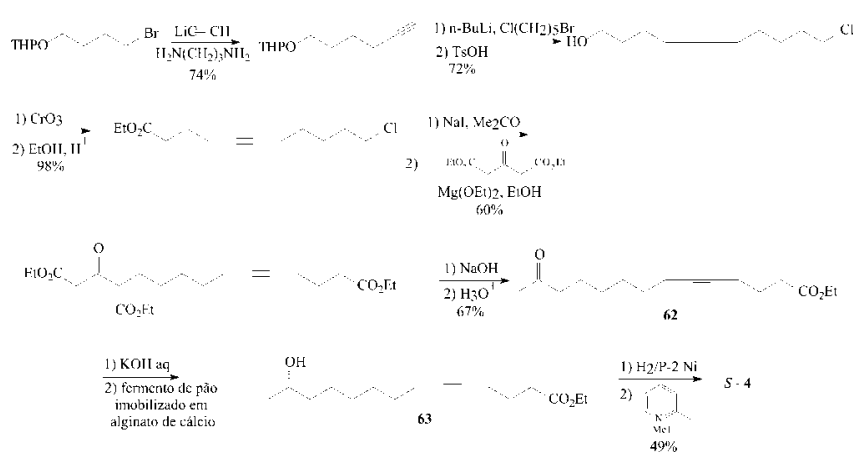

Esquema 27 
(3S,4R)-3,7-dimetil-6-octen-4-olida (64), conhecida como eldanolida, é o feromônio do macho da broca africana da cana-deaçúcar, Eldana saccharina. A síntese de $\mathbf{6 4}$ descrita faz a utilização do fermento de pão para a redução de $\gamma$-cetoácidos e formação do intermediário $R$-alcanolida (65) (Esquema 28) ${ }^{43}$.

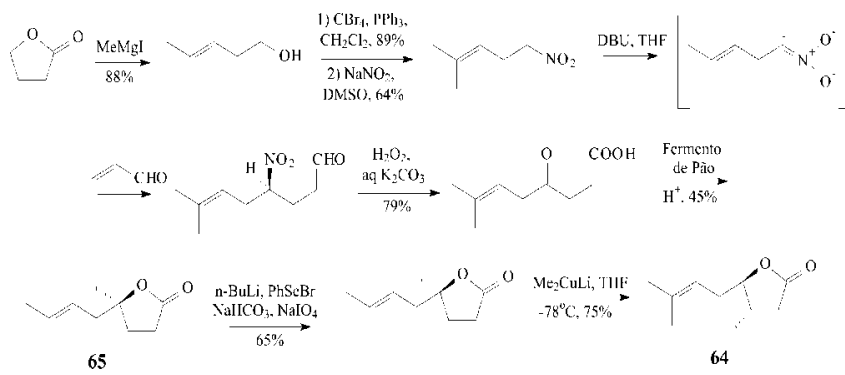

Esquema 28

\section{ISOPRENÓIDES}

O ácido callobruchúsico, ácido-[(E)-3,7-dimetil-2-octeno-1,8dióico]-(66), foi identificado como um dos compostos feromonais responsáveis pela copulação do besouro Callosobruchus chinesis (Coleoptera: Bruchidae), que induz o macho a expulsar seu órgão genital e tentar a copulação. O composto $\mathbf{6 6}$ foi preparado pela redução assimétrica de um aldeído com fermento de pão. A configuração absoluta do produto natural é ainda desconhecida, embora ambos os enantiômeros sejam ativos biologicamente, sendo que o isômero $(S)$ foi mais ativo que o seu antípodo $(R)$ - e significantemente próximo do feromônio natural ${ }^{44}$.

O diidroterpenediol, (E)-3,7-dimetil-2-octeno-1,8-diol (67), foi isolado por Meinwald et al. como o componente majoritário da secreção dos tufos de pêlos do último segmento abdominal do macho da mariposa monarca africana, Danaus chrysippus (Lepidoptera: Nymphalidae), e a configuração absoluta do composto é ainda desconhecida. Os autores relataram a síntese enantiosseletiva do composto $(S)-\mathbf{6 7}$ baseados na redução microbiológica com fermento de pão dos compostos carbonílicos ativados pela dupla ligação. A preparação do diidroterpenediol (67) e ácido callobruchusico (66) foi realizada partindo-se do mesmo intermediário, o geraniol (Esquema 29).

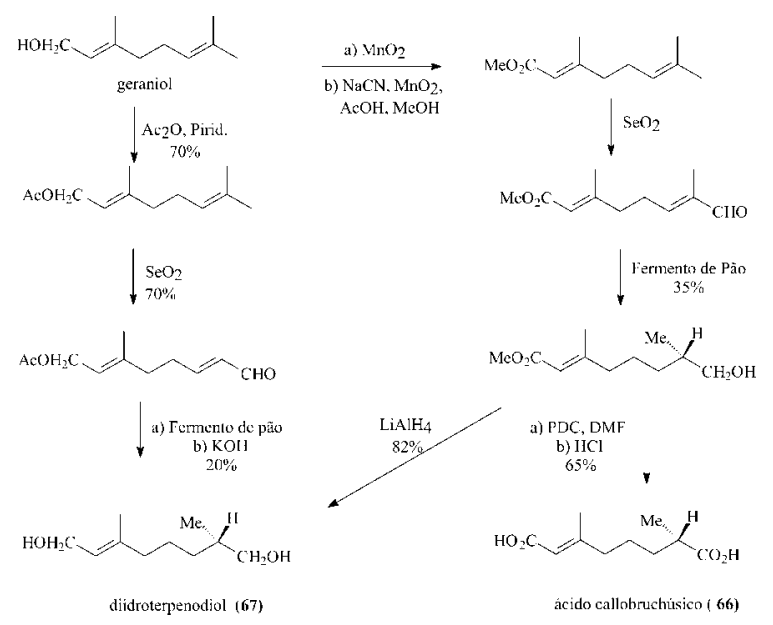

Esquema 29

A $(R)$-diidroactinidiolida, 2-oxo-4,4,7 $\alpha$-trimetil-2,4,5,6,7,7 $\alpha$ hexa-hidrobenzofurano (68), é componente do feromônio de reco- nhecimento da rainha da formiga lava-pés, Solenopsis invicta (Hymenoptera: Formicidae), juntamente com outras lactonas. Duas sínteses empregando fermento de pão são encontradas para este composto. A metodologia descrita no Esquema 30 emprega a redução assimétrica de 69 para fornecer 70 que leva ao composto 68 na configuração $R^{17}$. O Esquema 31 mostra a redução microbiológica da 3oxo-2,2,dimetilciclo-hexanona 71, que é precursor para a formação dos diastereoisômeros 72a e 72b, que foram separados e utilizados em etapas posteriores para fornecer o feromônio na configuração $S$ e $R^{45}$.
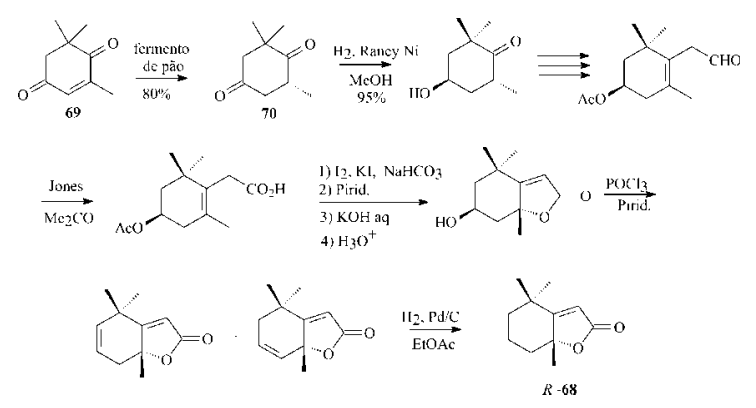

Esquema 30

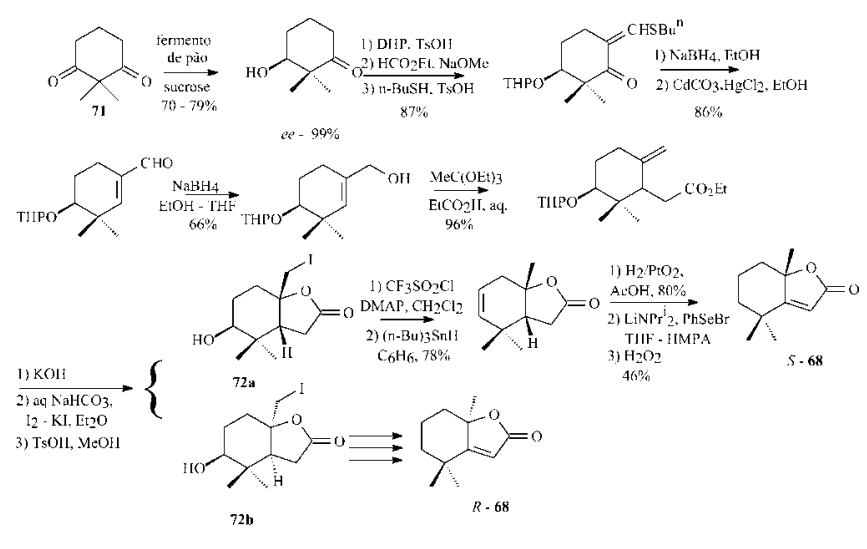

Esquema 31

\section{HETEROCICLOS CONTENDO OXIGÊNIO}

A 6-etil-2-metil-2,3-diidro-4H-piran-4-ona (73) é um dos componentes da mistura feromonal dos machos da mariposa Hepialus hecta (Lepidoptera: Hepialidae), sendo que a configuração do feromônio natural foi determinada como $(R)$-73, cuja síntese foi realizada através da redução de $\mathbf{7 4}$ com fermento de pão (Esquema $32)^{46,17}$.

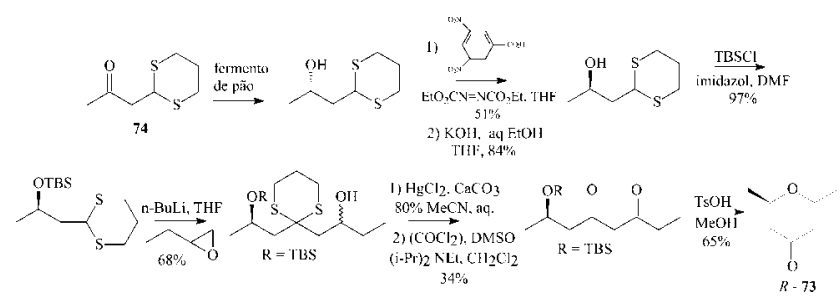

Esquema 32

A $\left(2 S, 3 R, 1^{\prime} R\right)$-estegobinona, [2,3,5-trimetil-6-(1'-metil-2oxobutil)-4H-piran-4-ona]-(75), é um dos dois componentes do 
feromônio sexual da fêmea do besouro Stegobium paniceum (Coleoptera: Anobiidae). A primeira síntese do composto natural $\left(2 S, 3 R, 1^{\prime} R\right)-75$ foi realizada por Hoffmann et al., de modo que a configuração $S$ na posição 2 foi obtida pela redução com fermento de pão do $\beta$-cetoéster 76. A mistura de 75 pode ser separada por cromatografia líquida de alta eficiência para fornecer a $\left(2 S, 3 R, 1^{\prime} R\right)$-estegobinona (75) e a $(2 S, 3 R, 1$ ' $S)$-epiestegobinona (75) (Esquema 33$)^{47}$.

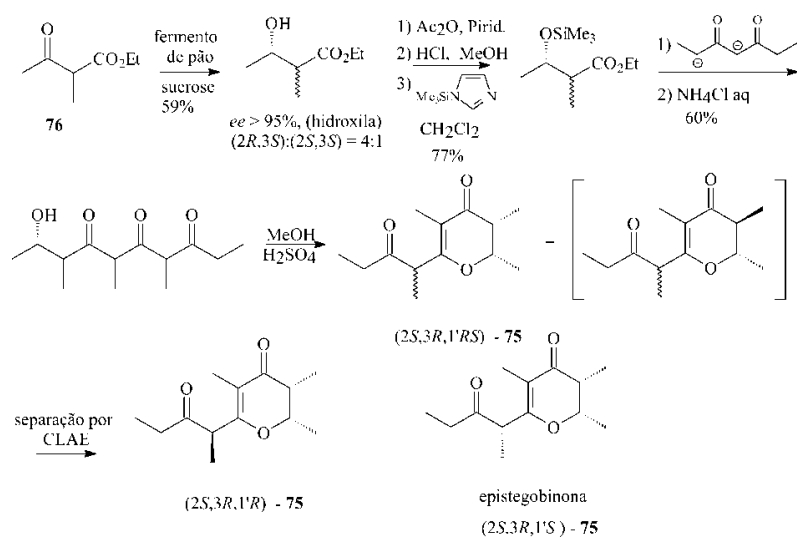

Esquema 33

\section{ACETAIS}

A (1S,5R)-frontalina (1,5-dimetil-6,8-dioxabiciclo[3.2.1]octano) (77) é o feromônio produzido pela fêmea do besouro do pinheiro, Dendroctonus frontalis (Coleoptera: Scolytidae), e por machos de D. brevicomis. O besouro de outra espécie, D. pseudotsugae, também utiliza 77 como componente feromonal ${ }^{17,48}$.

Três metodologias empregando fermento de pão foram descritas para a síntese de $\mathbf{7 7 ^ { 4 8 - 5 1 }}$. Fuganti et al. reduziram o $\alpha$-metilcinamaldeído para fornecer 78, que foi então convertido em 79. Adição seletiva do reagente de Grignard forneceu $\mathbf{8 0}$ e este, após modificações, levou à formação de 77 (Esquema 34$)^{49}$.

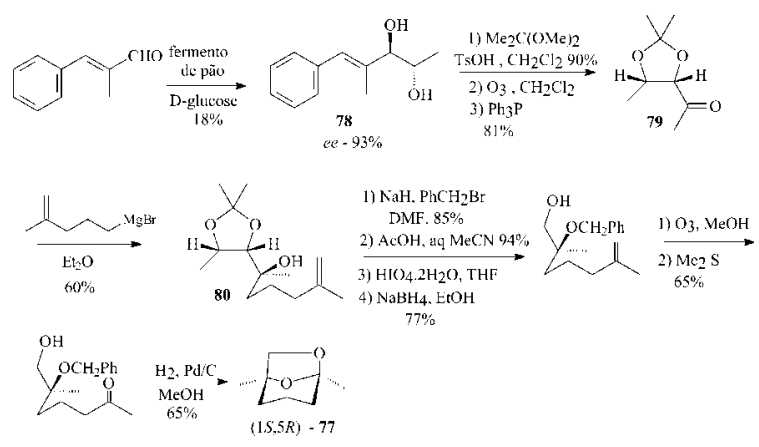

\section{Esquema 34}

Sato et al. reduziram o $\beta$-cetotioéster $\mathbf{8 1}$ para dar o hidroxitioéster

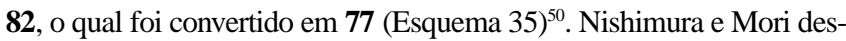
crevem uma rota sintética mais curta, sendo que em 10 etapas, a partir do $\beta$-cetoéster 83, a frontalina $\mathbf{7 7}$ pode ser obtida (Esquema 36$)^{51}$.

O exo-brevicomim (84) é o feromônio de agregação dos besouros Dendroctonus breviconis e Dryocetes confusus (Coleoptera: Scolytidae), enquanto o endo-brevicomin (85) é o feromônio dos escolitídeos Dendroctonus frontalis e Dryocetes autographus. A resposta de agregação de $D$. frontalis para captura, quando atraídos com frontalina (77), pode ser aumentada pela presença de (+)-85, enquanto (-)-85 reduziu significantemente esta resposta ${ }^{17}$.

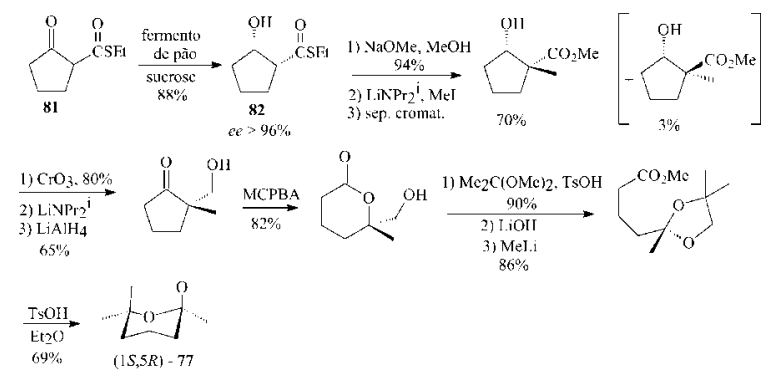

Esquema 35

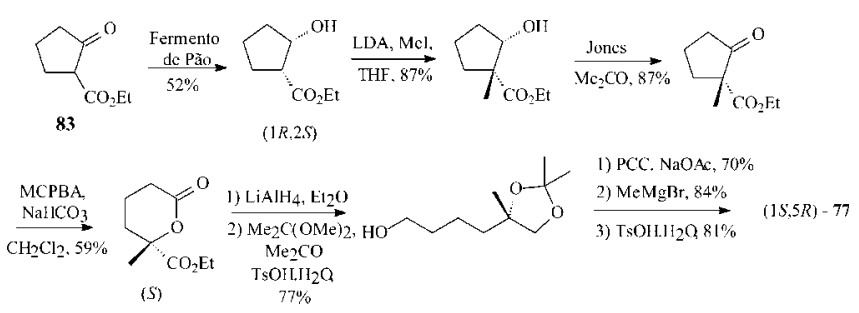

Esquema 36

Uma das sínteses desses enantiômeros foi realizada por Ramaswamy et al., baseada na resolução cinética com fermento de pão de $\mathbf{8 6}$ para fornecer $\mathbf{8 7}$ que, após as transformações necessárias, forneceu ( \pm )-84 e (+)-85 (Esquema 37$)^{52}$.

Outra metodologia foi empregada por Noda et al., que reduziram 88 com fermento de pão para dar $\mathbf{8 9}$, o qual foi convertido em 85, via redução diastereosseletiva da hidroxicetona 90 (Esquema 38$)^{53}$.

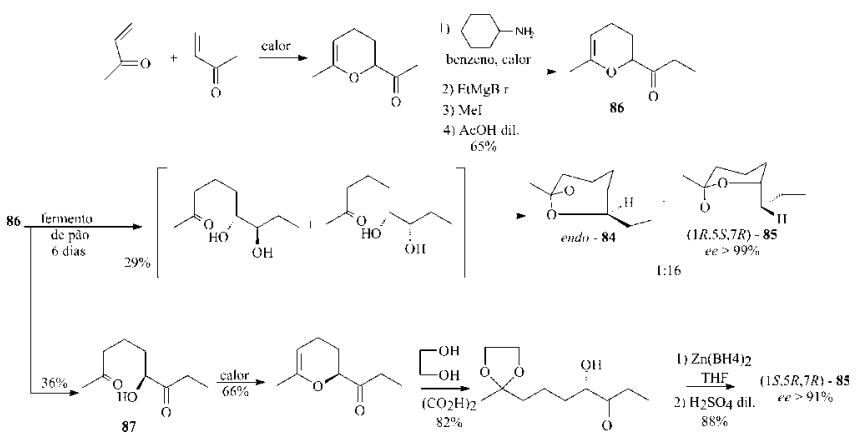

Esquema 37

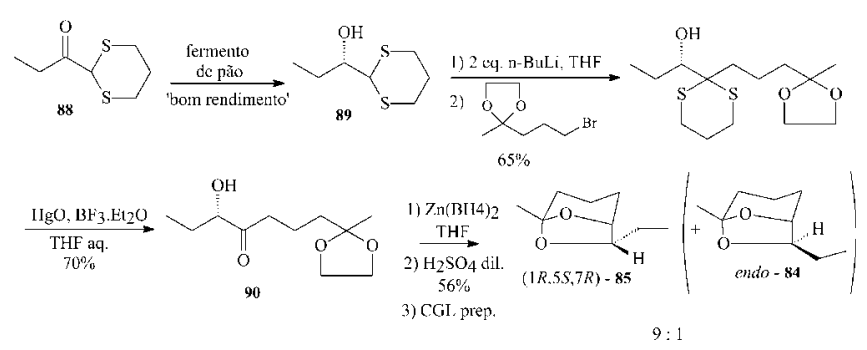

Esquema 38

$\mathrm{O}(1 R, 3 S, 5 S)$-1,8-dimetil-3-etil-2,9-dioxabiciclo[3.3.1]non-7-eno (91) e a $(1 R, 3 S, 5 R)$-1,8-dimetil-3-etil-2,9-dioxabiciclo[3.3.1]non-7ene-6-ona (92) são componentes do feromônio produzido pelo macho da mariposa Hepialus hecta (Lepidoptera: Hepialidae). Na sín- 
tese deste feromônio, o fermento de pão foi empregado para a obtenção do composto 93 levando ao precursor furano 94 (Esquema 39) ${ }^{54}$.

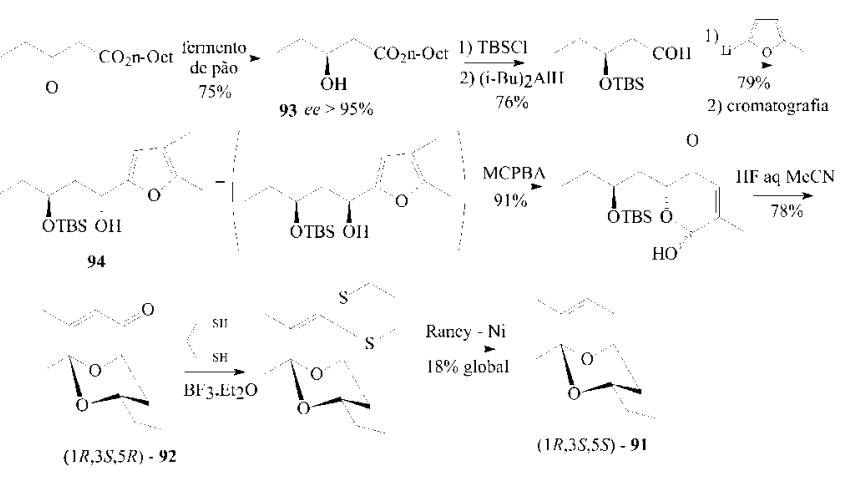

Esquema 39

\section{ESPIROACETAIS}

O (2S,6R,8S)-2,8-dimetil-1,7-dioxaspiro[5.5]undecano (95) é o componente majoritário da secreção cefálica de Andrena wilkella (Hymenoptera: Andrenidae), dentre os seis possíveis enantiômeros, além disso, este isômero foi bioativo no patrulhamento atrativo das abelhas macho no campo ${ }^{17}$. Mori sintetizou $(2 S, 6 R, 8 S)$ - e $(2 R, 6 S, 8 S)$ 95 utilizando redução microbiológica, obtendo altos valores de excesso enantiomérico ${ }^{17,55}$. O $(2 S, 6 R, 8 S)$-95 também foi preparado por Cohen et al. pela redução microbiológica da cetona 96 (Esquema 40$)^{56}$.

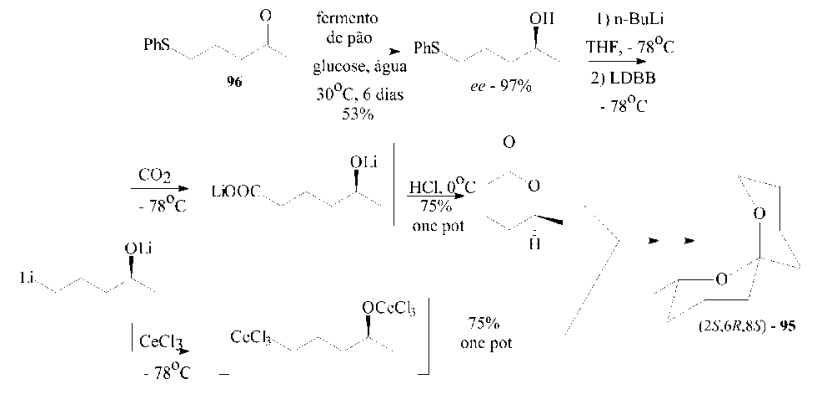

Esquema 40

O (2S,5R,7S)-2,7-dimetil-1,6-dioxaspiro[4.6]undecano (97) e (2S,5R,7S)-2,7-dietil-1,6-dioxaspiro[4.6]undecano (98) são os componentes feromonais de Andrena haemorrhoa e A. wilkella. A biorredução da cetona usando fermento de pão forneceu o diol que é o precursor para ambos compostos (Esquema 41$)^{57}$.

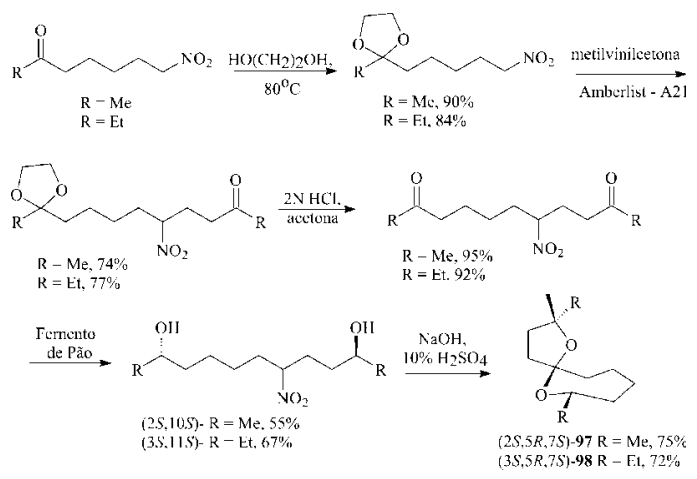

\section{CONCLUSÕES}

Procurou-se nesta revisão colaborar com os estudos relacionados com síntese de feromônios e biocatálise. Como pode ser visto, o emprego de fermento de pão, tanto em reações de redução quanto em resoluções cinéticas, tem se mostrado uma alternativa bastante simples e eficiente na síntese de feromônios.

\section{AGRADECIMENTOS}

À FAPESP, CAPES, CNPq e IFS (Suécia) pela ajuda financeira e bolsas de estudo e à L. G. B. Pereira pela ajuda com a nomenclatura dos insetos.

\section{REFERÊNCIAS}

1. Ferreira, J. T. B.; Corrêa, A. G.; Vieira, P. C.; Produtos Naturais no Controle de Insetos, EdUFSCar: São Carlos, 2001.

2. Koutek, B.; Streinz, L.; Romanuk, M.; Collect. Chem. Commun. 1998, 63, 899 .

3. Belan, A.; Bolte, J.; Fauve, A.; Gourcy, J. G.; Veschambre, H.; J. Org. Chem. 1987, 52, 256.

4. Mori, K.; Tetrahedron 1981, 37, 1341.

5. Pinheiro, S.; Ferreira, V. F.; Quim. Nova 1998, 21, 312.

6. Schoffers, E.; Golebiowski, A.; Johnson, C. R.; Tetrahedron 1996, 52, 3769. Kawai, Y.; Tsujimoto, M.; Kondo, S.-I.; Takanobe, K.; Nakamura, K.; Ohno, A.; Bull. Chem. Soc. Jpn. 1994, 67, 524. Davis, B. G.; Boyer, V.; Nat. Prod. Rep. 2001, 18, 618 .

7. Baraldi, P. T.; Corrêa, A. G.; Zarbin, P. H. G.; Vieira, P. C.; Tetrahedron: Asymmetry 2002, 13, 621.

8. Högberg, H.-E.; Berlung, P.; Edlund, H.; Fägerhag, J.; Hedenström, E.; Lundh, M.; Nordin, O.; Servi, S.; Vörde, C.; Catal. Today 1994, 22, 591.

9. Besse, P.; Ciblat, S.; Canet, J-L.; Troin, Y.; Veschambre, H.; Tetrahedron: Asymmetry 1999, 10, 2213.

10. Geresh, S.; Valiyaveettil, T.J.; Lavie, Y.; Shani, A.; Tetrahedron: Asymmetry 1998, 9, 89. Mori, K.; Bull. Soc. Chim. Belg. 1992, 101, 393; Mori, K.; Ebata, T.; Tetrahedron 1986, 42, 4413; Mori, K.; Kisida, H.; Tetrahedron 1986, 42, 5281.

11. Mori, K.; Takinaka, H.; Tetrahedron 1990, 46, 4473.

12. Naoshima, Y.; Nakamura, A.; Nishiyama, T.; Haramaki, T.; Mende, M.; Munakata; Y.; Chem. Lett. 1989, 1023. Naoshima, Y.; Nakamura, A.; Munakata, Y.; Kamezawa, M.; Tachibana, H.; Bull. Chem. Soc. Jpn. 1990, 63, 1263.

13. Wong, C. H.; Whitesides, G. M.; Enzymes in Synthetic Organic Chemistry, Tetrahedron Organic Chemistry, Series 12, Pergamon: Oxford, 1995.

14. Faber, K.; Biotransformations in Organic Chemistry, $2^{\mathrm{a}}$ ed., SpringerVerlag: Berlin, 1995.

15. Fuganti, C.; Grasselli, P.; Servi, S.; Högberg, H. E.; J. Chem. Soc. Perkin Trans. 1 1988, 3061.

16. Mori, K.; Mori, H.; Sugai, T.O.; Tetrahedron 1985, 41, 919.

17. Mori, K. Em The Total Synthesis of Natural Products; ApSimon; J., ed.; vol. 9, Wiley: New York, 1991.

18. Poppe, L.; Novak, L.; Devenyi, J.; Szantay, C. S.; Tetrahedron Lett. 1991, 32, 2643. Li, J.; Gries, G.; Gries, R.; Bikic, J.; Slessor, K. N.; J. Chem. Ecol. 1993, 19, 2547.

19. King, G. G. S.; Gries, R.; Gries, G.; Slessor, K. N.; J. Chem. Ecol. 1995, 21, 2027; Hoffmann R. W.; Ladner, W.; Helbig, W.; Liebigs Ann. Chem. 1984, 1170.

20. Fuganti, C.; Grasselli, P.; Servi, S.; Högberg, H. E.; J. Chem. Soc. Perkin Trans. 1 1988, 3061.

21. Sato, T.; Itoh, T.; Fujisawa, T.; Tetrahedron Lett. 1987, 28, 5677.

22. Hoffmann R. W.; Ladner, W.; Helbig, W.; Liebigs Ann. Chem. 1984, 1170.

23. Ferreira, J. T. B.; Simonelli, F.; Tetrahedron 1990, 46, 6311.

24. Itoh, T.; Yonekawa, Y.; Sato, T.; Fujisawa, T.; Tetrahedron Lett. 1986, 27, 5405 .

25. Archelas, A.; Furstoss, R.; Tetrahedron Lett. 1992, 33, 5241.

26. Li, Y.; Chen, Z. X.; Shi, C. Y.; Chin. J. Org. Chem. 2000, 20, 388; Sakai, T.; Hamamoto, H.; Mori, K.; Agric. Biol. Chem. 1986, 50, 1621.

27. Kharisov, R. Y.; Petukhova, N. I.; Davletova, A. R.; Ishmuratova, N. M.; Zorin, V. V.; Ishmuratov, G. Y.; Tolstikov, G.A.; Chem. Nat. Comp. 2000, $36,210$.

28. Takeuchi, Y.; Mori, K.; Biosci., Biotechol., Biochem. 1993, 57, 1967. 
29. Schumuff, N. R.; Phillips, J. K.; Burkholder, W. E.; Chen, C. W.; Roller, P. P.; Ma, M.; Tetrahedron 1984, 25, 1533; Phillips, J. K.; Walgenbach, C. A.; Klein, J. A.; Burkholder, W. E.; Schumuff, N. R.; Fales, H. M.; J. Chem. Ecol. 1985, 11, 1263.

30. Fujisawa, T.; Mobele, B. I.; Shimizu, M.; Tetrahedron Lett. 1992, 33, 5567.

31. Fuganti, C.; Grasseli, P.; Servi, S.; Spreafico, F.; Zirotti, C.; J. Org. Chem. 1984, 49, 4087.

32. Pilli, R. A.; Riatto, V. B.; J. Braz. Chem. Soc. 1999, 10, 363.

33. Pilli, R. A.; Riatto, V. B.; J. Braz. Chem. Soc. 1998, 9, 571.

34. Bel-Rheid, R.; Fauve, A.; Veschambre, H.; J. Org. Chem. 1989, 54, 3221.

35. Mori, K.; Mori, H.; Sugai, T. ; Tetrahedron 1985, 41, 919; Ghosh, S. K.; Chattopadhyay, S.; Mamdapur, V. R.; Tetrahedron 1991, 47, 919.

36. Kozikowski, A.P.; Murgrage, B. B.; Li, C. S.; Felder, L.; Tetrahedron Lett. 1986, 27, 4817.

37. Sato, T.; Okumura, Y.; Itai, J.; Fujisawa, T.; Chem. Lett. 1988, 1537.

38. Ramaswamy, S.; Oehlschlager, A.; Tetrahedron 1991, 47, 1145; Pirkle, W. H.; Adams, P. E.; J. Org. Chem. 1979, 44, 2169.

39. Katsuki, T.; Yamaguchi, M.; Tetrahedron Lett. 1987, 28, 651.

40. Servi, S.; Tetrahedron Lett. 1983, 24, 2023; Fujisawa, T.; Itoh, T.; Nakai, M.; Sato, T.; Tetrahedron Lett. 1985, 26, 2023.

41. Utaka, M.; Watabu, H.; Takeda, A.; J. Org. Chem. 1987, 52, 4363; Utaka, M.; Watabu, H.; Takeda, A.; Chem. Lett. 1985, 1475.
42. Tusobi, T.; Furutani, H.; Utaka, M.; Takeda, A.; Tetrahedron Lett. 1987, 28, 2709; Guo-Qiang, L.; Hai-Jian, X.; Bi-Chi, W.; Guong-Zhong, G.; WeiShan, Z.; Tetrahedron Lett. 1985, 26, 1233.

43. Sarmah, B. K.; Barua, N. C.; Tetrahedron 1993, 49, 2253.

44. Gramatica, P.; Gardina, G.; Speranza, G.; Manitto, P.; Chem. Lett. 1985, 1395.

45. Mori, K.; Nakazono, Y.; Tetrahedron 1986, 42, 283.

46. Ghiringhelli, D.; Tetrahedron Lett. 1983, 24, 287.

47. Hoffmann, R. W.; Ladner, W.; Steinbach, K.; Massa, W.; Schmidt, R.; Snatze, G.; Chem. Ber. 1981, 114, 2786.

48. Payne, T.L.; Richerson, J. V.; Dickens, J. C.; West, J. R.; Mori, K.; Berisford, C. W.; Hedden, R. L.; Vité, J. P.; Blum, M. S.; J. Chem. Ecol. 1982, 11, 1359.

49. Fuganti, C.; Graselli, P.; Servi, S.; J. Chem. Soc., Perkin Trans. 1 1983, 241.

50. Sato, T.; Maeno, H.; Fujisawa, T.; Chem. Lett. 1988, 1739.

51. Nishimura, Y.; Mori, K.; Eur. J. Org. Chem. 1998, 233.

52. Ramaswany, S.; Oehlschalger, A.; J. Org. Chem. 1989, 54, 255.

53. Noda, Y.; Kikuchi, M.; Chem. Lett. 1989, 1755.

54. De Shong, P.; Lin, M.-T.; Perez, J. J.; Tetrahedron Lett. 1986, 27, 2091

55. Mori, K.; Tanida, K.; Tetrahedron 1981, 37, 3221.

56. Cohen, T.; Tong, S.; Tetrahedron 1997, 53, 9487.

57. Bez, G.; Bezbarua, M. S.; Saikia, A. K.; Barua, N. C.; Synthesis 2000, 537. 